\title{
A Knot of the Central Catheter Created During Usage Period
}

\author{
Hektor Sula ${ }^{\mathrm{a}, \mathrm{d}}$, Rudin Domia, Artur Hafizi ${ }^{\mathrm{b}}$, Klodiana Spahiuc, Edi Spahiu ${ }^{\mathrm{c}}$
}

\begin{abstract}
The use of central veins catheters for diagnostic and therapeutic purposes is a common procedure in intensive care unit (ICU) and operating rooms. This procedure, even if performed by skillful hands, might cause complications during the insertion maneuvre or in the course of use. Preventing and decreasing the rate of the complications requires a correct technique application, from the insertion to the withdrawal procedure of the catheter. We are describing a rare complication case, which occurred a few days after the insertion of the catheter. The mechanisms of the presented complication must be rare, but is potentially possible.
\end{abstract}

Keywords: Deep vein; Central vein catheter; Complications

\section{Introduction}

Central venous catheter (CVC) insertion is an important and frequent procedure in the management of intensive care unit (ICU) patients. The use of CVC is essential for hemodynamic monitoring and drug administration, parenteral nutrition, dialysis in ICU but it can also reduce the patient discomfort and the number of peripheral punctures when long-term or multiple IV access is needed. Numerous methods and routes

Manuscript accepted for publication April 4, 2011

${ }^{\mathrm{a}}$ Deparment of Anesthesia and Intensive Care, University Hospital Center "Mother Theresa", Tirana, Albania

${ }^{b}$ Human Anatomy Department, Faculty of Medicine University of Tirana, Tirana, Albania

${ }^{\mathrm{c}}$ Civil Hospital, Durres, Albania

${ }^{\mathrm{d} C}$ Corresponding Author: Hektor Sula. Email: hektorsula@yahoo.com

doi:10.4021/jmc211w for CVC insertion exist, each with inherent advantages and risks. The most frequently used central veins are the subclavian, internal jugular, and femoral veins.

\section{Case Report}

The patient S.C. 65 years old, female, ASA 3, undergone to the cardiac surgery for the aortic valve replacement and tricuspid valve angioplasty. A central vein (right internal jugular vein) was cannulated using a $7 \mathrm{fr}$ double lumen catheter (ARROW). The procedure was uneventful and an X-Ray examination (immediately after the procedure) of the thorax confirmed the correct position (Fig. 1). The surgery was uneventful.

Due to postoperative respiratory failure, the patient was re-intubated and mechanically ventilated.

After that, the patient was transferred in the surgical intensive care unit for further respiratory assistance. A surgical tracheotomy was performed, because of prolonged mechanical ventilation. Nine days after the insertion procedure, the catheter, which was used in order to administer the drugs, was moved incidentally, and considering that the sterile drape was intact, the catheter was moved to be re-positioned,

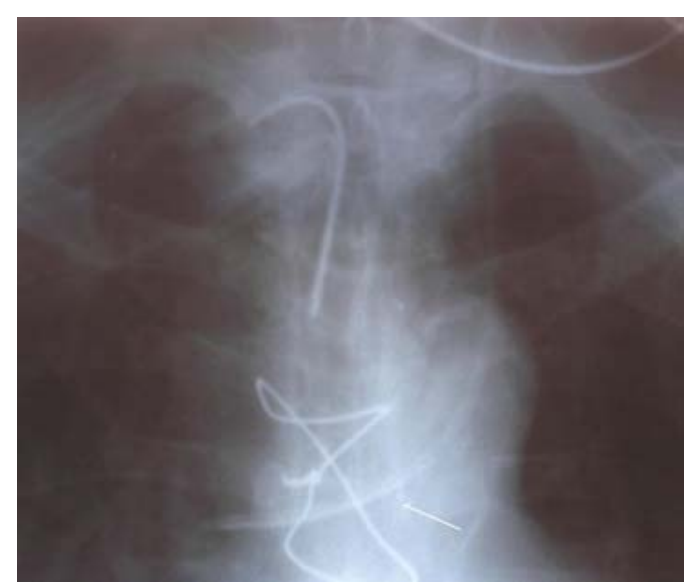

Figure 1. The X-ray examination demonstrating the correct position of central vein catheter. 


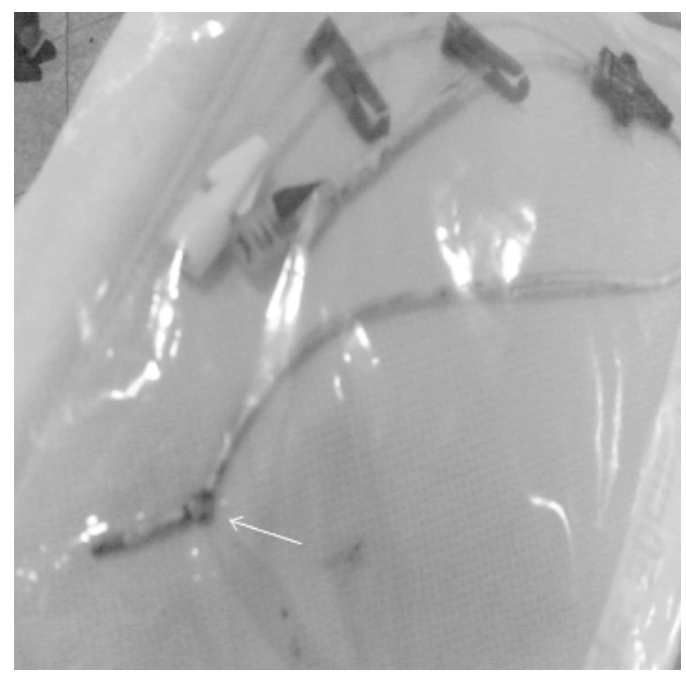

Figure 2. A knot in the central vein catheter.

without functional problems. The following day, during the removal trial, there was resistance in the last 5-6 cm, giving the impression of a possible accidental suturation during the tracheotomy procedure. After a few very cautious trials of removal, the catheter was pulled out. It was found to have a strangulative node 4-5 cm from the tip (Fig. 2), which must have been created during the manipulation of the previous day, initially creating a lasso without damaging its function, and which must have been tightened up during the removal trials. Fortunately, there was no infection or hemorrhage after catheter's removal.

\section{Discussion}

The main uses of the CVC are for hemodynamic monitoring, fluids and drugs infusions, total parenteral nutrition, hemodialysis, plasmapheresis or transvenous cardiac pacing. Common access sites include the subclavian, internal jugular, and femoral veins. The insertion of the catheter on the central veins also carry the risk of complications during the insertion procedures, or during their usage period. Concerning this problem, in the following table are selected the adverse effects and their rates during large-vein cannulation maneuvers (Table 1) [1].

Besides this group of more frequent complications, other much rarer complications are listed and described by different authors. In this category belongs also the so called knotting and kinking complication [2-4], caused mainly by the insertion procedure, presenting a difficulty in withdrawing the catheter. This complication can be prevented by insertion a not too long catheter, which may coil around itself in the atria $[5,6]$.

The correct technique must be applied during the insertion, as well as during all the period of the usage and the maintenance of the central catheters. Proper line care can minimize the complications.

Our presented case illustrates one of the possible complications which happened some days after the CVC insertion procedure was performed. We have not found the description of a similar case in the consulted literature.

Applying correct measures during all the course of patient's treatment will help to prevent such possible complications, which may in turn require additional interventions to be solved.

\section{Conflict of Interest}

The corresponding author had full access on data, no conflicts of interests, and no source of financial support. Not presented in any Congress.

Table 1. Adverse Effects of Large-vein Cannulation

\begin{tabular}{lccc}
\hline \multirow{2}{*}{ Adverse effects } & \multicolumn{3}{c}{ Complication rates (\%) } \\
\cline { 2 - 4 } & Subclavian vein & Internal jugular vein & Femoral vein \\
\hline Arterial puncture & $1-15$ & 3 & 9 \\
Major bleeding & 2 & 1 & 1 \\
Occlusive Thrombosis & 1 & 0 & 6 \\
Pneumothorax & $1-3$ & 1 & - \\
Systemic sepsis & $1-4$ & $0-8$ & $2-5$ \\
\hline
\end{tabular}

From: Marino L.P. The ICU Book Lippincott Williams Wilkins, third edition 2007, 117 (1). 


\section{References}

1. Marino L. Paul. Establishing venous access. In: The ICU Book. Third edition Lippincott Williams \& Wilkins. 2007, 117.

2. Brenner Simon Vascular procedures. In: Emergency Procedures and Techniques. Williams \& Wilkins 1994, 397.

3. McGee WT, Ackerman BL, Rouben LR, Prasad VM, Bandi V, Mallory DL. Accurate placement of central venous catheters: a prospective, randomized, multicenter trial. Crit Care Med. 1993;21(8):1118-1123.

4. McGee DC, Gould MK. Preventing complications of central venous catheterization. $N$ Engl $\mathrm{J}$ Med. 2003;348(12):1123-1133.

5. Johansson C, Malmstrom G, Uggla LG. Insertion of subclavian line: don’t get knotted. JAMA 1970; 214; 373-4.

6. Pachai A. Guidewire knot formation during insertion of a central venous catheter. Ugeskr Laeger. 1997;159(37):5534-5535. 